\title{
Segmented Nature of the Himalaya and Gangetic Plain
}

\section{B Parkash*, Rajat S Rathor, AK Awasthi, Pitambar Pati, Balaji Bhosle, Rajendra P Jakhmola, Seema Singh and Vivekanand Acharya}

Department of Earth Sciences, Indian Institute of Technology Roorkee, Roorkee -247 667, INDIA

*For correspondence, email: bparkfes@iiyr.ernet.in

The Ganga River terraces near Hardwar, in eastern part of the Dehradun Valley, northwestern Himalaya, close to the Himalayan Frontal Thrust (HFT), formed due to movements along this thrust. These terraces give overall uplift rate, slip rate and convergence rates $8.26 \pm 1.67 \mathrm{~mm} / \mathrm{yr}, 16.57 \pm 3.35 \mathrm{~mm} / \mathrm{yr}$ and $14.31 \pm 2.90 \mathrm{~mm} / \mathrm{yr}$, respectively. These rates are similar to those reported from the western part of the valley and are significantly less than those published from Eastern Nepal Himalaya. The Eastern Nepal Himalaya is also marked by the many high peaks $(>8000 \mathrm{~m})$, resulting in high sediment loads of rivers originating therein. The Middle and Lower Gangetic Plains adjoining to this segment of the Himalaya show high rates of subsidence, a narrow width and major sedimentation by large rivers in the form of megafans of rivers like the Gandak, Kosi and Teesta. The reverse is true of the northwestern Himalaya including the western Nepal, which has a lower relief $(<7000 \mathrm{~m})$, low sediment load of the rivers originating in this segment and low convergence rates along the HFT. The adjoining (Upper) Gangetic Plain is wide, mainly uplifted in nature (forming interfluves with moderately to well-developed soils) and incised by large rivers. These plains also show signatures of extensional tectonics. Thus, the Himalaya and adjoining Gangetic Plain are both segmented in nature and these are due to different quasi-equilibriums prevailing in the two segments, in terms of rates of convergence and underthrusting, and uplift of ranges and width of the adjoining plains. 